\title{
ОСОБЕННОСТИ ИНТЕЛЛЕКТУАЛЬНОГО РАЗВИТИЯ МЛАДШИХ ШКОЛЬНИКОВ ПРИ ПЕРЕХОДЕ К ОБУЧЕНИЮ В ОСНОВНОЙ ШКОЛЕ
}

\author{
Каргин М.И., Смирнов Е.А.
}

Федеральное государственное бюджетное образовательное учреждение высшего образования «Мордовский государственный педагогический институт имени М.Е. Евсевьева», г. Саранск, Российская Федерация

В статье раскрываются различные подходы к определению термина «интеллектуальное развитие», разъясняются особенности интеллектуального развития младиих икольников, его взаимосвязь со школьной успеваемостью. Автором представлены даннье теоретического анализа научных трудов по теме, результаты исследования, позволяющего определить особенности интеллектуального развития младиих школьников при переходе к обучению в средней школе.

Ключевые слова: интеллект; интеллектуальное развитие; икольная успеваемость; психика; младший школьный возраст; эксперимент.

\section{FEATURES OF INTELLECTUAL DEVELOPMENT OF JUNIOR SCHOOLCHILDREN DURING THE TRANSITION TO PRIMARY SCHOOL}

\section{Kargin M.I., Smirnov E.A.}

Mordovian state pedagogical Institute named after M.E. Evseveva, Saransk, Russian Federation

The article reveals different approaches to the definition of the term "intellectual development», explains the features of intellectual development of younger students. The author presents the data of theoretical 
analysis of scientific works on the topic, the results of the study, which allows to determine the features of intellectual development of younger students in the transition to secondary school.

Ключевые слова: intelligence; intellectual development; academic performance; psyche; primary school age; experimental study.

\section{Введение}

Проблема исследования интеллекта занимает особое место в психологической науке в связи со стремлением исследователей оценить возможности ума человека, как важнейшего органа познания как самого себя, так и явлений окружающей действительности.

Понятие интеллектуального развития личности рассматривается в психолого-педагогической литературе с различных точек зрения: усвоенные знания, определенная структура умственных действий (М.К. Акимова, В.Т. Козлова [1]); как величина динамичная, способная к развитию в процессе обучения (И.А. Горчакова [2]); сторона психического развития ребенка, его познавательной сферы (Е.С. Логинова [3]); процесс, подчиненный генетическим и возрастным факторам (Ж. Пиаже [5]); процесс, который подчинен принципу системной дифференциации (Т.А. Ратанова [6]).

Учет закономерностей возрастных изменений развития интеллекта в обучении школьников особенно актуален в сенситивные периоды развития личности, одним из которых является младший школьный возраст. Основным показателем интеллектуального развития младших школьников традиционно считается академическая успеваемость. Высокий уровень интеллектуального развития младших школьников при переходе к обучению в средней школе является важным условием усвоения учебного материала, способствует овладению любой другой деятельностью, оказывает влияние на общий уровень школьной успеваемости учащегося. Но как демонстрирует исследование литературы проблема взаимосвязи интеллектуального развития и успеваемости в младшем школьном возрасте в исследованиях ориентируется только косвенно, что и определяет проблему нашего исследования. 


\section{Материалы и методы исследования}

Нами было проведено исследование с целью изучения интеллектуального развития младших школьников. В исследовании приняли участие 45 испытуемых 4 класса в возрасте 10-11 лет, обучающиеся в МОУ «Средняя общеобразовательная школа № 32» г. о. Саранск Республика Мордовия.

В исследовании мы опирались на методологию системно-контекстной психодиагностики [4], которая, утверждает, что без учета контекста снижается прогностическая ценность диагностических методик, а результаты могут иметь лишь обобщенное значение [7]. Положения СКП-диагностики позволили нам перейти к изучению уровня умственного развития школьников.

Для изучения умственного развития учащихся нами был использован «Групповой интеллектуальный тест (ГИТ)».

\section{Результаты исследования}

Всех учащихся 4 класса мы разделили на две группы. Ученики с высоким уровнем академической успеваемости и с низким уровнем академической успеваемости. Их распределение было осуществлено по журналу в связи с их успеваемостью. Ученики, которые имели средний бал 4,5-5 мы отнесли к группе с высоким уровнем академической успеваемости (24 человека). Ученики, имеющие средний балл 3-3,5 мы отнесли к группе с низким уровнем академической успеваемости (21 человек).

Рассмотрим уровень умственного развития учеников с высоким уровнем академической успеваемости. В группе учеников с высоким уровнем академической успеваемости интеллектуальный уровень выше нормы был обнаружен у 29,2\% учащихся; у 62,5\% - в рамках возрастной нормы; у 8,3\% - близкий к возрастной норме; низкий и очень низкий результат у школьников не был диагностирован. Для учеников с высоким уровнем академической успеваемости было характерно: высокая понятливость, способность к быстрому реагированию на инструкции, гибкость нервной системы (субтест «Исполнение инструкций»); широкие познания в области матема- 
тики, владение математическими навыками и действиями (субтест «Арифметические задачи»); широкий словарный запас, высокая осведомленность в области русского языка, способность к вычленению смысла предложений, правильному построению предложений (субтест «Дополнение предложений»); умение анализировать понятия, сравнивать их на основе выделения существенных признаков (субтест «Определение сходства и различия понятий»); высокая способность к установлению закономерности последовательности чисел (субтест «Числовые ряды»); высокая степень развития умения логических отношений (субтест «Установление аналогий»); высокие скоростные возможности выполнения простой умственной работы, низкая утомляемость (субтест «Символы»).

Рассмотрим уровень умственного развития учеников с низким уровнем академической успеваемости. В группе учеников с низким уровнем академической успеваемости интеллектуальный уровень выше нормы не был обнаружен у учащихся; у 19\% - в рамках возрастной нормы; у 28,6\% - близкий к возрастной норме; у 42,9\% низкий уровень; у 9,5\% - очень низкий результат. Для учеников с низким уровнем академической успеваемости было характерно: затруднения в восприятии предложенных инструкций, не внимательность, медленное овладение понятиями и умственными действиями, слабая выраженность лабильности нервной системы (субтест «Исполнение инструкций»); фрагментарные математическими знания и навыки (субтест «Арифметические задачи»); низкая осведомленность по русскому языку, ограниченность словарного запаса, не способность к осмысливанию предложения, низкий навык правильного построения предложения, либо его отсутствие (субтест «Дополнение предложений»); низкое умение устанавливать сходство и различие между понятиями (субтест «Определение сходства и различия понятий»); низкая способность к установлению закономерности последовательности чисел (субтест «Числовые ряды»); низкая степень развития умения логических отношений (субтест «Установление аналогий»); низкие скоростные возможности выполнения простой умственной работы, высокая утомляемость (субтест «Символы»). 


\section{Обсуждение}

Полученные результаты исследования подтвердили гипотезу о взаимосвязи интеллектуального уровня развития учащихся со школьной успеваемостью. Успешность школьного обучения в младшем школьном возрасте на пороге перехода к обучению в средней школе в значительной степени определяется уровнем их интеллектуального развития. Проведенная диагностика позволила выявить учащихся, имеющих недостаточную результативность по показателям интеллектуального развития, для последующего оказания им своевременной индивидуальной педагогической и психологической поддержки.

\section{Заключение}

Успешность школьного обучения при переходе к обучению в средней школе во многом определяется уровнем интеллектуального развития ученика. Ученики с высоким уровнем академической успеваемости более подготовлены по школьным предметам, у них хорошо развиты все интеллектуальные способности, усвоенные знания, умения и навыки рассчитаны на их возраст. Ученики с низким уровнем академической успеваемости имеют значительные пробелы в освоении школьной программы, недостаточность общего кругозора, низкие показатели развития интеллектуальных способностей. Выявленные закономерности могут способствовать повышению эффективности при организации процесса интеллектуального воспитания школьников.

\section{Список литературы}

1. Акимова М.К., Козлова В.Т. Диагностика умственного развития детей. СПб.: Питер, 2006. 240 с.

2. Горчакова И.А. Формирование интеллектуальной деятельности в процессе обучения [Электронный ресурс] // Вестник Донецкого национального технического университета. 2008. № 1. С. 13-17.

3. Логинова Е.С. Особенности интеллектуального развития мальчиков и девочек 6-10 лет // Новые исследования. 2013. № 4 (37). С. 52-66. 
4. Каргин М.И. Методология деятельностного подхода в развитие СКПдиагностики / М. И. Каргин // Актуальные проблемы и перспективы развития современной психологии № 1. 2015. С. 117-124.

5. Пиаже Ж. Психология интеллекта // Избранные психологические труды. СПб.: Питер, 2004. 192 с.

6. Ратанова Т.А. Психофизиологические особенности интеллектуального развития старшего подростка // Психологический журнал. 1999. T. 20. № 2. C. 90-102.

7. Dementieva E.V. The Study of Professional Self-Determination of Russian High School Students in the Framework of the Systemic Contextual Psychodiagnostics / Elena V. Dementieva, Mikhail I. Kargin, Nadezhda F. Sukhareva // Astra Salvensis - review of history and culture, year VI, Special Issue 2018. C. 635-644.

\section{References}

1. Akimova M.K., Kozlova V.T. Diagnosis of mental development of children. SPb.: Peter, 2006. 240 p.

2. Gorchakova I.A. Formation of intellectual activity in the learning process [Electronic resource] // Bulletin of Donetsk national technical University. 2008. №. 1, pp. 13-17.

3. Loginova E.S. Features of intellectual development of boys and girls 6-10 years // New studies. 2013. № 4 (37), pp. 52-66.

4. Kargin MI Methodology of the activity approach to the development of the CTP-diagnostics / M.I. Kargin // Actual problems and development prospects of modern psychology № 1. 2015, pp. 117-124.

5. Piaget J. Psychology of intelligence // Selected psychological works. SPb.: Peter, 2004. 192 p.

6. Ratanova T.A. Psychophysiological features of intellectual development of an older teenager / / Psychological journal. 1999. Vol. 20. №. 2, pp. 90-102.

8. Dementieva E.V. The Study of Professional Self-Determination of Russian High School Students in the Framework of the Systemic Contextual Psychodiagnostics / Elena V. Dementieva, Mikhail I. Kargin, Nadezhda F. Sukhareva // Astra Salvensis - review of history and culture, year VI, Special Issue 2018. C. 635-644. 